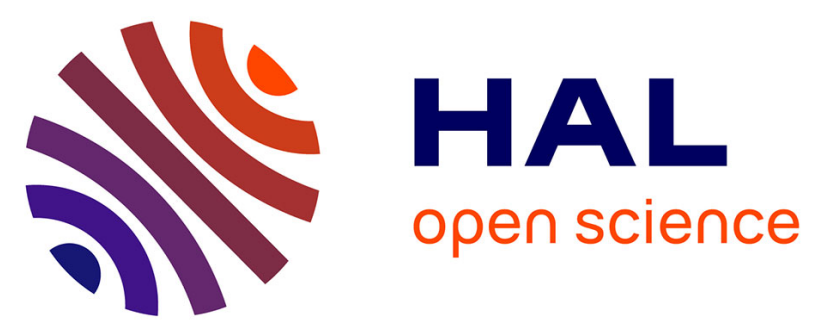

\title{
Efficient 2.45 GHz rectenna design including harmonic rejecting rectifier device
}

Hakim Takhedmit, Laurent Cirio, Boubekeur Merabet, Bruno Allard, François

Costa, Christian Vollaire, Odile Picon

\section{- To cite this version:}

Hakim Takhedmit, Laurent Cirio, Boubekeur Merabet, Bruno Allard, François Costa, et al.. Efficient $2.45 \mathrm{GHz}$ rectenna design including harmonic rejecting rectifier device. Electronics Letters, 2010, 46 (12), 10.1049/el.2010.1075 . hal-03122017

\section{HAL Id: hal-03122017 https://hal.science/hal-03122017}

Submitted on 26 Jan 2021

HAL is a multi-disciplinary open access archive for the deposit and dissemination of scientific research documents, whether they are published or not. The documents may come from teaching and research institutions in France or abroad, or from public or private research centers.
L'archive ouverte pluridisciplinaire HAL, est destinée au dépôt et à la diffusion de documents scientifiques de niveau recherche, publiés ou non, émanant des établissements d'enseignement et de recherche français ou étrangers, des laboratoires publics ou privés. 


\section{Efficient $2.45 \mathrm{GHz}$ rectenna design including harmonic rejecting rectifier device}

H. Takhedmit, L. Cirio, B. Merabet, B. Allard, F. Costa, C. Vollaire and O. Picon

An efficient rectenna based on a dual Schottky diodes converter has been designed at $2.45 \mathrm{GHz}$. The proposed rectifying circuit is well suitable for wireless sensor applications because no input lowpass filter and no via-hole connections are required, resulting in a more simple structure. A simulation mixing an electromagnetic and circuit analysis has been first used to optimise the rectifier. In addition, the performances of the rectenna has been correctly predicted and characterised using an FDTD formulation extended to lumped circuit elements. The realised rectenna exhibits $83 \%$ efficiency over a $1050 \Omega$ resistive load at a power density of $0.31 \mathrm{~mW} / \mathrm{cm}^{2}$.

Introduction: The rectenna is an important component for converting $\mathrm{RF}$ or microwave power into DC power. These techniques are of great interest to supply actuators [1] or wireless sensors [2] through free space without wire connections or a battery. A rectenna usually contains a receiving antenna, a combination of one or several Schottky diodes in series [3] or shunt [4], in voltage doubler configurations [5] or in a modified bridge converter [6], an input lowpass filter (LPF), an output DC pass filter and a resistive load. The input (LPF) rejects harmonics created by the diodes and provides matching between the antenna and the rectifier. It can be directly included on the radiating element by using harmonic-rejecting antennas [7].

We propose an efficient rectenna design based on a dual diodes converter. In this configuration, the LPF between the antenna and diodes can be eliminated, reducing the insertion losses of the rectifier. The structure has been optimised and characterised using advanced design system (ADS) commercial software and the 3D-FDTD algorithm extended to lumped element circuits. Finally, simulated results are compared with the measured ones and show good agreement

Rectenna design: The rectenna shown in Fig. 1 is printed on ARLON $25 \mathrm{~N}$ substrate with $\varepsilon_{r}=3.38$ and $1.524 \mathrm{~mm}$ thickness. It contains a linearly polarised rectangular patch antenna designed at $2.45 \mathrm{GHz}$ by using ADS Momentum software. The rectenna contains two HSMS2860 commercial Schottky diodes in a SOT23 package. These diodes have forward and breakdown voltages of 0.3 and $7 \mathrm{~V}$, respectively. The zero bias junction capacitance $C_{j 0}$ is $0.18 \mathrm{pF}$ and the series resistance $R_{s}$ is $5 \Omega$.

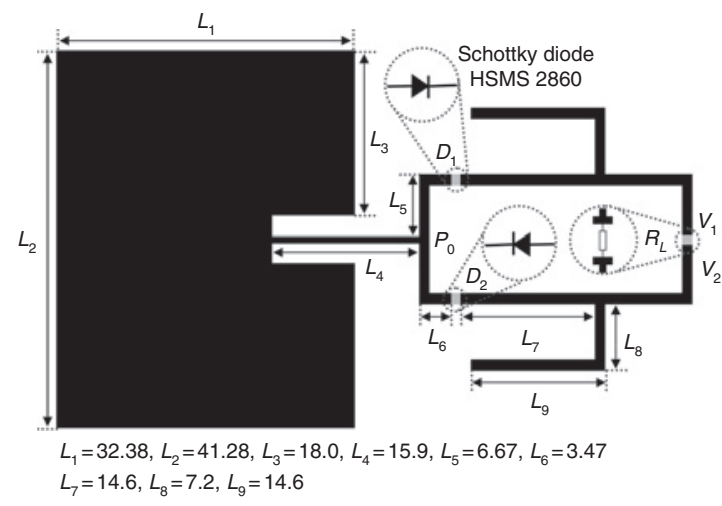

Fig. 1 Geometry of rectenna (dimensions in millimetres)

The simulated input impedance of the diode is $95-j 200 \Omega$ at $2.45 \mathrm{GHz}$ and $10 \mathrm{dBm}$ input RF power. The optimised symmetric lines (length $L_{7}$ ) are used to tune the reactance at the input of the diodes. All the lines have a characteristic impedance $\left(Z_{0}\right)$ of $87 \Omega$ except at the input of the circuit where a $100 \Omega$ microstrip line is used as the feeding line. These lines are chosen to match the input of the rectifier with the patch antenna.

The DC voltage is obtained by measuring the voltage difference between $V_{1}$ and $V_{2}$ across the resistor load, without reference to the $\mathrm{RF}$ ground plane. Therefore, there is no need for any via-holes.

The $2.45 \mathrm{GHz}$ power yields from the antenna is split into two separated equivalent RF components, which propagate in phase on both symmetrical and parallel $87 \Omega$ microstrip lines towards diodes $D_{1}$ and $\mathrm{D}_{2}$. The RF signal is then partially converted into DC current with unwanted higher-order harmonics.

To correctly optimise the efficiency of the rectifier, simulations were carried out with the aid of ADS software. A coupling between Momentum (for the distributed part) and Harmonic Balance (including the nonlinear model of the diode) has been performed. A 'gradient' method was also used to optimise the rectifier by means of a criterion based on the conversion efficiency. Here, the parameters (lengths of the microstrip lines and load) have been computed for an input power of $10 \mathrm{dBm}$. We have obtained an optimised $1050 \Omega$ resistor load and dimensions, as shown in Fig. 1.

FDTD numerical results: We have computed the current distribution on transmission lines by using the full-wave 3D-FDTD algorithm including linear and nonlinear lumped circuit elements extension. In addition, the total-field/scattered-field formulation has also been included to realise an arbitrary plane-wave illumination on the rectenna [8]. The rectenna is illuminated by a linearly polarised incident plane wave of $20 \mathrm{~V} / \mathrm{m}$ $\left(0.106 \mathrm{~mW} / \mathrm{cm}^{2}\right)$ at its broadside. Current distributions are given after fast-Fourier transform (FFT) computation. The DC current flows through $\mathrm{D}_{1}, \mathrm{D}_{2}$ and $R_{L}$ without reference to the $\mathrm{RF}$ ground plane.

Fig. 2 shows the current distribution on the structure at $2.45 \mathrm{GHz}$. The rectifier contains two folded quarter-wavelength open-circuited stubs that act as short-circuits (a peak of current appears on the main lines). These stubs block the unwanted $2.45 \mathrm{GHz} \mathrm{RF}$ component flowing from the diodes to the resistive load.
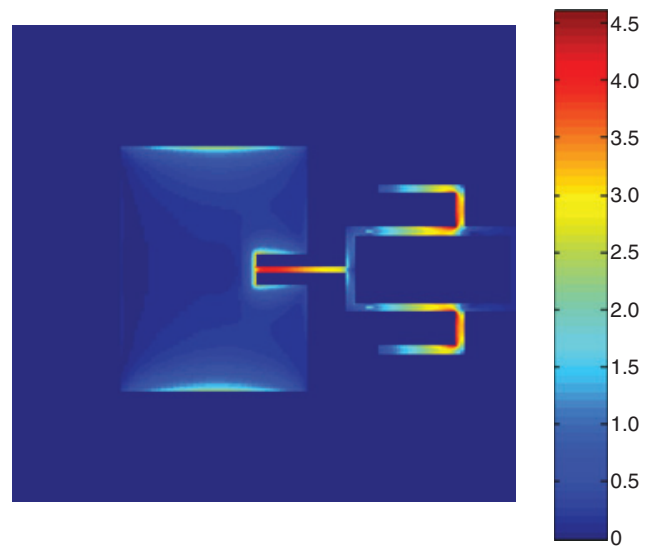

Fig. 2 Current distribution $(\mathrm{A} / \mathrm{m})$ at $2.45 \mathrm{GHz}$

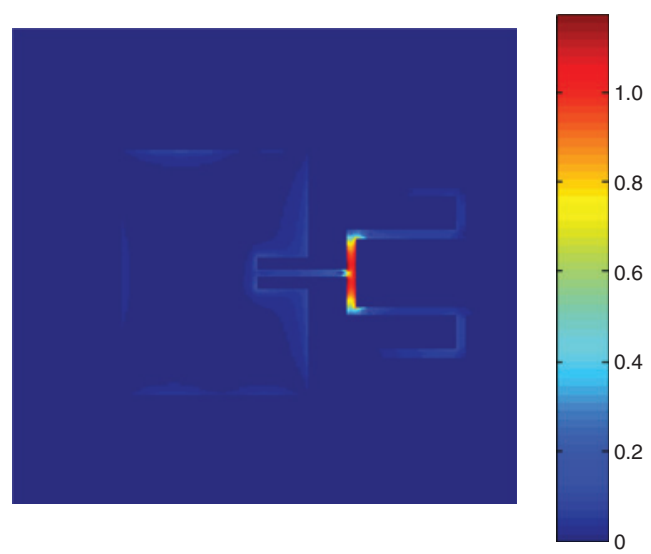

Fig. 3 Current distribution $(\mathrm{A} / \mathrm{m})$ at $4.9 \mathrm{GHz}$

Fig. 3 shows the current distribution at $4.9 \mathrm{GHz}$. The diodes have been accurately localised on a null of current to minimise the power losses. In addition, owing to the half-wavelength distance between the diodes at $4.9 \mathrm{GHz}$, the second harmonic is then distributed by a standing wave with a peak of current at the input of the circuit $\left(P_{0}\right)$, resulting in a short-circuit. The second harmonic generated by the nonlinear diodes has been confined and there are no propagation effects towards the microstrip antenna, where no current exists at $4.9 \mathrm{GHz}$, and the resistive load. The $7.35 \mathrm{GHz}$ third harmonic is largely reduced $(-30 \mathrm{~dB}$ 
attenuation) and there is a mismatch between the antenna and the rectifier at this frequency. Therefore, the efficiency is not affected.

Rectenna measurements: The linearly polarised patch antenna has been measured in an anechoic chamber. It exhibits a gain of $4.7 \mathrm{~dB}$ and a minimum return loss of $-20 \mathrm{~dB}$ at $2.45 \mathrm{GHz}$. Results agree well with those obtained by Momentum software. The output DC voltage and overall efficiency have been measured against power density from the Friss transmission equation [1] and considering a distance of $70 \mathrm{~cm}$ between the transmitting linearly polarised horn antenna $\left(G_{\text {trans }}=\right.$ $12 \mathrm{~dB})$ and the rectenna under test. On the transmitter side, we have used a $30 \mathrm{~dB}$ gain power amplifier at $2.45 \mathrm{GHz}$ connected to a signal generator. The output DC voltage across the resistor load has been measured by a voltmeter.

The FDTD simulated and measured output DC voltages and overall efficiencies are shown in Fig. 4. In the power density range $\left(0-0.31 \mathrm{~mW} / \mathrm{cm}^{2}\right)$, the measured rectenna efficiency is above $80 \%$ from $0.22 \mathrm{~mW} / \mathrm{cm}^{2}$ power density $(E=29 \mathrm{~V} / \mathrm{m})$ and the corresponding output DC voltage is $2.6 \mathrm{~V}$ over a $1050 \Omega$ optimised load resistance. FDTD and measured results are in good agreement and clearly show that the output voltage and efficiency increase when the power density increases.
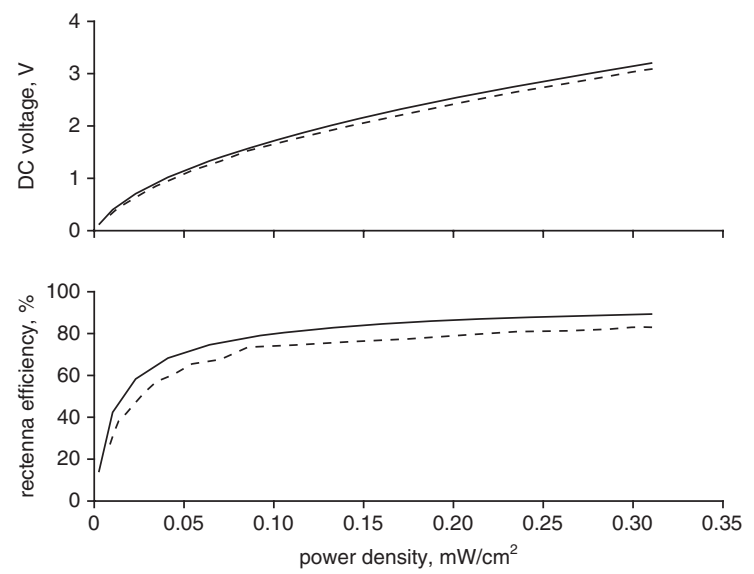

Fig. 4 Simulated and measured DC voltages and rectenna efficiencies against power density

FDTD method

measured

Conclusions: We propose an efficient rectenna design, based on a dualdiode circuit topology. Owing to the symmetry of the rectifier and the optimised length of the lines and load, no input lowpass filter is needed, thus reducing the insertion losses and the dimensions of the circuit. In addition, owing to the differential DC measurements, no via-holes are necessary. The rectifying circuit has been optimised at $2.45 \mathrm{GHz}$ for an input power of $10 \mathrm{dBm}$. The rectenna exhibits a measured efficiency of $83 \%$ at $0.31 \mathrm{~mW} / \mathrm{cm}^{2}$ power density and an output DC voltage of $3.1 \mathrm{~V}$. These results are very close to those obtained by full-wave FDTD simulations. This rectenna should have applications for remote power supply and the driving of small actuators and sensors.

Acknowledgment: This work is part of the Wave Supply project, which was supported by the Aeronautic and Space Foundation.

(C) The Institution of Engineering and Technology 2010

20 April 2010

doi: $10.1049 / \mathrm{el} .2010 .1075$

One or more of the Figures in this Letter are available in colour online.

H. Takhedmit, L. Cirio and O. Picon (ESYCOM, University of Paris-Est Marne-la-Vallée, Cité Descartes, Marne-la-Vallée 77454, France)

E-mail: hakim.takhedmit@ec-lyon.fr

B. Allard and C. Vollaire (AMPERE-UMR 5005, EC-INSA Lyon, 36 Av. Guy de Collongue, 69130, France)

B. Merabet and F. Costa (SATIE-UMR 8029, ENS Cachan, 61 Av. du président Wilson, Cachan 94235, France)

H. Takhedmit: Also with AMPERE-UMR 5005, EC-INSA Lyon, France

\section{References}

1 Epp, L.W., Khan, A.R., Smith, H.K., and Smith, R.P.: 'A compact dualpolarized $8.51-\mathrm{GHz}$ rectenna for high-voltage $(50 \mathrm{~V})$ actuator applications', IEEE Trans. Microw. Theory Tech., 2000, 48, (1), pp. $111-120$

2 Farinholt, K.M., Park, G., and Farrar, C.R.: 'RF energy transmission for a low-power wireless impedance sensor node', IEEE Sensors J., 2009, 9 (7), pp. 793-800

3 Suh, Y.H., Wang, C., and Chang, K.: 'Circularly polarised truncatedcorner square patch microstrip rectenna for wireless power transmission', Electron. Lett., 2000, 36, (7), pp. 600-602

4 Ren, Y.J., and Chang, K.: '5.8-GHz circularly polarized dual-diode rectenna and rectenna array for microwave power transmission', IEEE Trans. Microw. Theory Tech., 2006, 54, (4), pp. 1495-1502

5 Yo, T.C., Lee, C.M., Hsu, C.M., and Luo, C.H.: 'Compact circularly polarized rectenna with unbalanced circular slots', IEEE Trans. Antennas Propag., 2008, 56, (3), pp. 882-886

6 Takhedmit, H., Merabet, B., Cirio, L., Allard, B., Costa, F., Vollaire, C., and Picon, O.: 'A $2.45 \mathrm{GHz}$ low cost and efficient rectenna'. European Conf. on Antennas and Propagation (EuCAP 2010), Barcelona, Spain, April 2010

7 Park, J.K., Han, S.M., and Itoh, T.: 'A rectenna design with harmonicrejecting circular-sector antenna', IEEE Antennas Wirel. Propag. Lett., 2004, 3, pp. 52-54

8 Taflove, A., and Hagness, S.C.: 'Computational electrodynamics - the finite difference time domain method' (Artech House Inc., 2005, 3rd edn) 